\title{
An Urban Forest Effects (UFORE) model study of the integrated effects of vegetation on local air pollution in the Western Suburbs of Perth, WA
}

\author{
S.M. Saunders ${ }^{1}, \underline{\text { E. Dade }^{1}}$ and K. Van Niel ${ }^{1}$ \\ ${ }^{1}$ University of Western Australia (UWA), Crawley, Western Australia \\ Email: sandra.saunders@uwa.edu.au
}

\begin{abstract}
Managing vegetation in urban environments requires an understanding of its structure, atmospheric interactions and function. This has led to quantification and development of models to estimate the functions of urban vegetation, particularly the integrated effects that take place between vegetation and local atmospheres. The Urban FORest Effects (UFORE) model (developed in North America by the U.S Forest Service (USFS)) provides a method of quantifying multiple functions of urban vegetation including the structure, deposition of air pollutants, emission of biogenic volatile organic compounds (BVOCs), carbon store and annual carbon sequestration, and identifies those species which are most effective at improving local air quality. It has had limited international applications and has not been applied to an Australian environment. This study applied UFORE to the vegetation on public owned land contained in several western suburbs of Perth, Western Australia.
\end{abstract}

Differences in vegetation and air quality between Australia and North America were analysed to assess the applicability of this model to an urban Australian environment. There are many complex processes involved in both the removal of pollutants from the local atmosphere and the emission of BVOCs, which are currently unknown or difficult to model (such as dispersion of pollutants at different scales, physiological differences in vegetation between climatic regions and the effect of resource limitations on plant growth). However the results of this study provide a first approximation of the influence vegetation has on a local urban atmosphere in Western Australia. The results show an overall net removal of air pollutants (294 tonnes annually) when compared to BVOC emissions (119 tonnes annually). It is recognised that individual air pollutants vary in structure and reactivity, and there can also be significant spatial variability in the removal of pollutants by vegetation, hence this should be taken into account when planning the location of new vegetation establishments.

While the Perth region does not yet have significant air quality issues, this analysis provides a greater understanding of how vegetation selection can impact local air quality and identifies the potential for UFORE to influence public planning and policy. Incorporating the atmospheric function of vegetation into planning early can ensure that the species composition and level of vegetation in the area will provide the maximum atmospheric benefits as the population grows and pollutant emissions increase

In addition to traditional air pollution abatement strategies, vegetation can contribute to the air quality of local urban atmospheres, and is seen as a relatively cost effective method of reducing pollutant levels. Identification and incorporation of local data into UFORE will allow estimates of urban vegetation functions to be improved and lead to wider use of the model in Australian urban environments.

Keywords: Urban vegetation, air pollution, BVOC, UFORE model 


\section{INTRODUCTION}

The benefits and functions of urban vegetation have received growing interest from both urban ecology researchers and town planners. Of particular importance is the role of urban vegetation in the modification of the local atmosphere, including both removal and emission of harmful atmospheric pollutants. Many researchers have attempted to model and quantify this role to better understand the contribution of vegetation to improving air quality and sustainability in urban areas, with the majority of research conducted in the U.S and Europe. The incorporation of vegetation into air quality management plans is not a new concept. In the early 1930s it was used in Moscow to provide clean air and recreation to citizens (Boentje \& Blinnikov 2007). The type of vegetation used for the purpose of managing air quality must be able to tolerate the conditions experienced in urban environments including increased concentrations of air pollutants, the features of urban soils and the local climate, yet still have a significant lifespan as removal and replacement costs can be high (Yang et al. 2005).

Within a region the composition and sources of air pollutants are not static; they vary with changes in industry, per capita income, number and type of motor vehicles, and government policies (Bokwa 2008; Fenger 1999; Kreyling et al. 2003; White 1994a). Hence monitoring of air pollutants is essential, especially in fast-growing cities such as Perth, Western Australia. Here, a network of monitoring stations measure air pollutants as defined by the National Environmental Protection Measure (NEPM) for Ambient Air Quality; $\mathrm{CO}, \mathrm{NO}_{2}$, photochemical oxidants (measured as $\mathrm{O}_{3}$ ), $\mathrm{SO}_{2}$, lead and $\mathrm{PM}_{10}$ (particulate matter $<10 \mu \mathrm{m}$ ) (Department of Environmental Protection 2000). In Perth the NEPM standards are rarely exceeded; in 2006 there were only 5 exceedences and all were for $\mathrm{PM}_{2.5}(\mathrm{PM}<2.5 \mu \mathrm{m})$, caused by prescribed bushfire management of fire-prone areas or low wind conditions causing a recirculation of air and accumulation of wood-smoke (Department of Environment and Conservation 2007). The meteorology of the Perth region can also lead to exceedences in $\mathrm{O}_{3}$ in summer with high sunlight, hot temperatures and oscillating wind patterns recirculating the air (Environmental Protection Authority 2007).

The Perth region's growth, combined with scattered suburbs and increased car dependence (and hence pollutant emissions) can greatly influence future air quality. Urban sprawl can also be significant for vegetation through clearing of native vegetation for development and an increase in the stresses experienced by urban vegetation. This is of particular importance for the Perth region, located in one of 20 global biodiversity hotspots (Myers et al. 2000). The unique and endemic nature of native plants in Australia, and the lack of research into their physiology present issues in modelling their role in atmospheric interactions within urban areas, so the full potential and contribution of urban vegetation to air quality has not yet been realised. This study, in collaboration with Western Regional Organisation of Councils (WESROC), applied the Urban FORest Effects (UFORE) model to vegetation on public owned land in several western suburbs of Perth, over two seasons (summer and winter 2008). UFORE developed by the U.S Forest Service (USFS, Nowak and Crane, 2000) models several vegetation-atmosphere interactions; the monthly amount of $\mathrm{SO}_{2}$, $\mathrm{NO}_{2}, \mathrm{CO}, \mathrm{O}_{3}$ and $\mathrm{PM}_{10}$ removed by the vegetation, along with the yearly rate of carbon sequestration and biogenic VOC (BVOC) emissions; using extensive vegetation, meteorological and air pollutant data. BVOC emissions generally exceed anthropogenic emissions on a global scale and are much more reactive than anthropogenic emissions, making BVOCs a large contributor to the formation of $\mathrm{O}_{3}$ and smog (Benjamin \& Winer 1998; Guenther et al. 1995). Overall the UFORE analysis in WESROC provides insight into the local atmospheric impact of the current species composition on public land, and identifies those species that are most effective at improving local air quality through deposition of pollutants.

\section{STUDY AREA}

Perth, the capital city of Western Australia is located in the south-west of the State. The region is predominantly flat, spanning approximately $5,500 \mathrm{~km}^{2}$. The climate is Mediterranean, with hot dry summers and cool wet winters. Air quality in this region is influenced by the seasonal meteorology. On calm cold nights temperature inversions can trap air pollutants near the ground resulting in elevated concentrations, while elevated temperatures and high sunlight in summer can promote the formation of photochemical smog (Department of Environmental Protection 2000). As is common in many coastal cities, Perth experiences a recirculation of air pollutants whereby early morning emissions pushed over the ocean by the land breeze can be brought back over the land in the afternoon by the developing sea breeze (Yimin \& Lyons 2003). The specific study area is located in the WESROC between Perth and Fremantle, extending between the coast and river as shown in Figure 1, with an area of 6,320 ha. The population in 2006 of the 6 councils participating in the study was approximately 80,000 (Australian Bureau of Statistics 2009). Most of land use in the area is residential and commercial with a small amount of industry (WESROC 2002). Vegetated areas in the study area are fragmented and characterised by large grassed areas and high levels of exotic species (Ficus macrophylla (Moreton Bay Fig) and Platanus $x$ acerifolia (London Planetree)) on streetscapes, developed 
parks, and institutional land, although about $10 \%$ of the area is remnant native vegetation (WESROC 2002). Of interest in this study was the vegetation located on public land within WESROC (education, hospitals, cemeteries, local government buildings, parks, recreation facilities and road reserves) accounting for $39 \%$ of the study area. A randomised grid-sampling pattern was used to select field-sampling sites. A $200 \mathrm{~m} \times 200 \mathrm{~m}$ grid was laid across a map of the study area and points randomly placed in a selected number of grid cells using a Geographic Information System (GIS), providing a good spatial spread across the area.

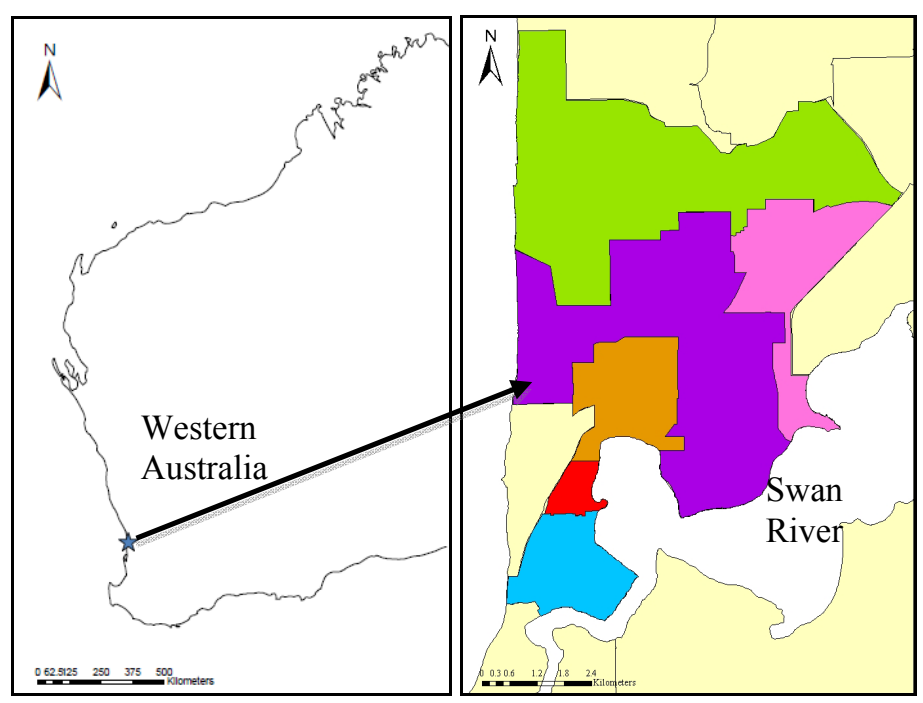

Figure 1 Land in WESROC study area.

\section{THE UFORE MODEL STRUCURE AND DATASETUP}

\subsection{Conceptual framework}

Though past research focus has been on the recreational and amenity value of urban vegetation (Niemelä 1999), increasing interest has been placed on environmental functions including the carbon stored in and sequestered annually by vegetation, the emission of BVOCs, and deposition of atmospheric pollutants. The UFORE model provides a method of quantifying these interactions between urban vegetation and the local atmosphere, by combining local data with current knowledge and parameterisations. Conducting a UFORE analysis involves multiple steps, as shown in Figure 2. It was used in the present study to estimate the amount of dry deposition of air pollutants, BVOC emissions, and carbon storage and sequestration, in vegetation located on public land in the study area.

\begin{tabular}{|c|c|}
\hline $\begin{array}{l}\text { 1) Identify data requirements } \\
\text { - Field data } \\
\text { Sample or complete inventory } \\
\text { Include shrub species or just } \\
\text { measure tree species } \\
\text { - Meteorological data } \\
\text { - Air pollutant concentration data } \\
\mathrm{O}_{3}, \mathrm{SO}_{2}, \mathrm{NO}_{2}, \mathrm{CO}, \mathrm{PM}_{10}\end{array}$ & $\begin{array}{l}\text { 2) Site selection } \\
\text { - Classify land use and select relevant land } \\
\text { uses for study (private/public land) } \\
\text { - Sampling pattern } \\
\quad \text { random } \\
\quad \text { grid } \\
\quad \text { stratified random } \\
\text { - Selection of field sampling sites }\end{array}$ \\
\hline $\begin{array}{l}\text { 4) UFORE model calculations } \\
\text { - Structural calculations } \\
\text { - } \text { BVOC emissions } \\
\text { - Carbon storage and annual sequestration } \\
\text { - Dry deposition of } \mathrm{O}_{3}, \mathrm{SO}_{2}, \mathrm{NO}_{2}, \mathrm{CO}, \\
\mathrm{PM}_{10}\end{array}$ & $\begin{array}{l}\text { 3) Field Sampling } \\
\begin{array}{r}\text { - Define plot size and shape } \\
\quad 20 \mathrm{~m} \text { diameter, circular plots } \\
\left(314.6 \mathrm{~m}^{2}\right)\end{array} \\
\text { - Collection of field data } \\
\text { - Enter field data into UFORE shell }\end{array}$ \\
\hline
\end{tabular}

\footnotetext{
Analysis of methods and results

- Effectiveness of model for Perth environment

- Limitations of methods and results

- Improvements for the model
}

Figure 2. Main steps involved in carrying out the UFORE analysis for WESROC

The functional calculations contained in UFORE are based on a number of field data, hourly meteorological (MET), and hourly pollutant concentration measurements, in this study for the period December 2007 November 2008. The MET parameters required were specified by the USFS and data obtained from the two closest Bureau of Meteorology (BoM) stations (Swanbourne and Mt Lawley), supplemented with more detailed data from the Perth Airport station. Several parameters were calculated from 3-hourly synoptic data. Hourly pollutant data were obtained from three Department of Environment and Conservation (DEC) 
monitoring stations within, or near to, the study area; Swanbourne, within the study area boundary, Duncraig to the north, and South Lake to the south. $\mathrm{O}_{3}$ and $\mathrm{NO}_{2}$ measurements were taken from Swanbourne station, $\mathrm{CO}$ and $\mathrm{PM}_{10}$ from Duncraig, and $\mathrm{SO}_{2}$ from South Lake.

Table 1 Average hourly pollutant concentrations; $\mathrm{O}_{3}, \mathrm{SO}_{2}$ and $\mathrm{CO}$ in ppb, $\mathrm{PM}_{10}$ in $\mu \mathrm{g} / \mathrm{m}^{3}$ (source DEC)

\begin{tabular}{llllllll}
\multicolumn{5}{c}{ Summer } & \multicolumn{5}{l}{ Winter } \\
\hline Pollutant & Dec 2007 & Jan 2008 & Feb 2008 & Jun 2008 & Jul 2008 & Aug 2008 \\
\hline $\mathrm{NO}_{2}$ & 3.5 & 3.8 & 4.9 & 9.5 & 8.8 & 9.6 \\
$\mathrm{O}_{3}$ & 22.3 & 20.6 & 23.2 & 18.7 & 20.9 & 19.6 \\
$\mathrm{SO}_{2}$ & 1.1 & 1.5 & 0.5 & 0.4 & 0.5 & 0.6 \\
$\mathrm{CO}$ & 121.0 & 150.1 & 108.1 & 407.9 & 552.3 & 387.7 \\
$\mathrm{PM}_{10}$ & 14.4 & 24.0 & 16.9 & 13.0 & 12.6 & 11.6 \\
\hline
\end{tabular}

Gaps and erroneous (negative) values in the data were replaced with the monthly averages of the relevant pollutant for the specific hour (Nowak et al. 2002). The final data (Table 1) show clear seasonal differences, particularly between summer and winter, with $\mathrm{NO}_{2}$ and $\mathrm{CO}$ concentrations markedly higher in winter. Field data provide local vegetation and land cover information. A total of 40 plots were initially sampled. At each, information on the land use, groundcover, shrub and tree characteristics (species, height, canopy dimensions) were measured. All plots located in remnant bushland were classified under the 'vacant' land use after consultation with the UFORE developers. As the equations used in UFORE classify 'park' trees as subject to improved growing conditions (pruning, watering, fertilization), the 'vacant land' classification was more representative of growth and maintenance conditions experienced in remnant bushland areas. Following the survey the study area was stratified into 3 land classes: public services (schools, libraries, hospitals), parks/recreation (developed and undeveloped parks, ovals, golf courses) and transportation (roads and road verges). Using the formula below based on the number of trees per plot, additional plots were placed in each land class, making a total of 76 plots:

$$
M_{k}(\alpha p t)=\sum M_{k} \times\left(\frac{\overline{N_{h}} \times S_{h}}{\Sigma\left(\overline{N_{h}} \times S_{h}\right)}\right)_{(1)}
$$

Where $M_{h}(o p t)$ is the optimal number of plots for the land class, $M_{h}$ and $\overline{N_{h}} \quad$ are the number of plots sampled and mean number of trees in each land class, and $S_{h}$ is the standard deviation for the land class. Once all the required data were gathered they were entered into UFORE by the USFS, providing output for analysis. UFORE uses information from a database of trees which contains the relevant data for structural and BVOC emission calculations obtained from literature sources. Although many common native Australian vegetation species are represented in the databse, for some less common species an equivalent 'replacement' species was determined after consultation with the USFS and Plant Biologists at UWA. Selection was primarily based on the closest relative from the same genera, or on structural, leaf and biomass characteristics that best represent the atmospheric role of the species (emissions and deposition). Details of the formulas used in UFORE to calculate the parameters and functions of the vegetation can be found in Nowak (1996), Nowak et al. (1998), Nowak \& Crane (2000) and Nowak et al. (2008).

\section{RESULTS AND DISCUSSION}

\subsection{Structure of the urban vegetation in WESROC}

There are an estimated $191,700( \pm 53,800)$ trees located on public land in WESROC. Tree cover is $22 \%$ while shrub cover is $12 \%$ (Table 2). Comparison between WESROC and several U.S cities shows tree cover in WESROC markedly higher than in San Francisco, CA (12\%) and Philadelphia, PA (16\%) and similar to Baltimore, MD (21\%) and New York, NY (21\%) (Nowak et al. 2007). Tree density was $83( \pm 23)$ trees/ha, higher than in many U.S cities which have had UFORE analyses conducted, including San Francisco, CA (9 trees/ha) and Brooklyn, NY (6 trees/ha) (Nowak et al. 2002; Nowak et al. 2007). Of the 63 species identified during field sampling, 30 were represented by a replacement species, generally by a similar species in the same genera. Based on the species input to UFORE (i.e. using replacement species), the following 4 genera were estimated to have the most individuals located in the study area: Eucalyptus $20,300( \pm 17,400)$, Acacia 45,100 $( \pm 40,000)$, Grevillea 25,000 $( \pm 13100)$ and Hakea 19,500 $( \pm 15,300)$. The majority of trees were in 'good' (1-10\% dieback) or 'excellent' ( $<1 \%$ dieback) condition ( $49 \%$ and $15 \%$ of trees respectively), with $9 \%$ classified as 'dead' $(100 \%$ dieback). Species in the worst condition were associated with remnant native bushland including Hakea laurina (used to represent all Banksia species) (12\% dead), Acacia cyclops (16\% 
dead) and Eucalyptus marginata (25\% dead). Table 2 summarizes the overall structural characteristics. Eucalyptus gomphocephala had the greatest leaf area density (LAD) $1,020( \pm 440) \mathrm{m}^{2} / \mathrm{ha}$ and greatest leaf biomass density $140( \pm 60) \mathrm{kg} / \mathrm{ha}$. Though LAD indicates those species currently providing the most surface area for pollutant deposition, a measure of leaf area per ground area (LAI) is a more useful indicator of those most effective for pollutant deposition. Species input to UFORE with a high LAI $>4.97$ are given in Table 3 .

Table 2. Summary of structural characteristics of vegetation situated on public land in WESROC

\begin{tabular}{|c|c|c|}
\hline Total \# trees & $\%$ tree cover & $\%$ shrub cover \\
\hline $191,700(83 / \mathrm{ha})$ & $22(66 \%$ evergreen $)$ & $12(49 \%$ evergreen $)$ \\
\hline Total leaf area $\left(\mathrm{km}^{2}\right)$ & Leaf area density $\left(\mathrm{m}^{2} / \mathrm{ha}\right)$ & $S p$. with highest leaf area density $\left(\mathrm{m}^{2} / \mathrm{ha}\right)$ \\
\hline 20 & 7,800 & $\begin{array}{l}\text { Eucalyptus gomphocephala }(1,020) \text { Rosa } x \text { alba }(610) \\
\text { Agonis flexuosa }(560)\end{array}$ \\
\hline $\begin{array}{l}\text { Total leaf biomass } \\
\text { (tonnes) }\end{array}$ & $\begin{array}{l}\text { Leaf biomass density } \\
\text { (kg/ha) }\end{array}$ & $S p$. with highest leaf biomass density (kg/ha) \\
\hline 1,830 & 790 & $\begin{array}{l}\text { Eucalyptus gomphocephala (140) Araucaria hetrophylla } \\
\text { (50) Grevillea noellii (50) }\end{array}$ \\
\hline
\end{tabular}

Table 3. WESROC species highest and lowest mean LAI

\begin{tabular}{lc} 
Species & Mean LAI \\
\hline Araucaria hetrophylla & 8.14 \\
Phoenix canariensis & 8.04 \\
Casuarina cunninghamiana & 5.01 \\
Platanus $x$ acerifolia & 4.97 \\
Eucalyptus marginata & 1.06 \\
Melaleuca decussata & 0.91 \\
Eucalyptus nicholii & 0.85 \\
\hline
\end{tabular}

\subsection{Dry Deposition of Air Pollution}

Meteorological conditions (particularly wind speed and direction) can influence pollutant dispersal and hence removal rate. In Perth winter months are generally characterised as calm with low average wind speeds, while summer months have strong easterly winds in the morning (9am) and strong south-westerly winds in the afternoon (3pm) (National Climate Centre 2008). Overall the Pollutant removal for $\mathrm{PM}_{10}$ from June-November was based on an incomplete data set, so the amount removed (6 tonnes) cannot be compared to annual removal of the other pollutants. Excluding PM $_{10}$ removal and standardised to grams of pollutants removed per $\mathrm{m}^{2}$ canopy area, the removal rate was $16.0 \mathrm{~g} / \mathrm{yr} / \mathrm{m}^{2}$ canopy area. This is in contrast to Brooklyn, NY where a markedly lower rate was estimated $\left(7.5 \mathrm{~g} / \mathrm{yr} / \mathrm{m}^{2}\right)$ and similar to San Diego, CA $\left(11.8 \mathrm{~g} / \mathrm{yr} / \mathrm{m}^{2}\right)$ (both excluding $\mathrm{PM}_{10}$ removal) (Nowak et al. 2002; Nowak, Crane \& Stevens 2006). Pollutant removal was greatest for $\mathrm{O}_{3}$ (183 tonnes, or $\left.62 \%\right)$, followed by $\mathrm{NO}_{2}(51$ tonnes), $\mathrm{CO}$ (45 tonnes), and $\mathrm{SO}_{2}$ (10 tonnes). $\mathrm{O}_{3}$ was also the greatest proportion of total pollutant removal in San Diego, CA (78 \%) and Brooklyn, NY (42\%) (Nowak, Crane \& Stevens 2006; Nowak et al. 2002). This trend was also shown in per area pollutant removal for Beijing, China, (Yang et al. 2005) and Brooklyn, $\mathrm{NY}$ where $\mathrm{O}_{3}$ removal per $\mathrm{m}^{2}$ land area was the highest of all pollutants measured (Table 4). Per area, pollutant removal was markedly lower than WESROC in both of these cities (Table 4). The lower value in Brooklyn can mainly be attributed to the lower evergreen vegetation (3.8\%) and cooler climate (Nowak et al. 2002). Peak pollutant removal varied for individual pollutants, with $\mathrm{CO}, \mathrm{NO}_{2}$ and $\mathrm{O}_{3}$ removal highest in July (9 tonnes), August ( 7 tonnes) and October (23 tonnes) respectively, whilst the peak removal of $\mathrm{SO}_{2}$ occurred in January ( 2 tonnes) (Figure 4). Monthly variation in average concentration of individual pollutants follows a similar trend to monthly pollutant removal rates. Strong correlation coefficients were observed for $\mathrm{CO}(0.99), \mathrm{NO}_{2}(0.98), \mathrm{PM}_{10}\left(0.93\right.$, June-November) and $\mathrm{SO}_{2}(0.96)$, however the correlation was lower for $\mathrm{O}_{3}(0.45)$.

Table 4 Annual pollutant removal per $\mathrm{m}^{2}$ of total area.

\begin{tabular}{|c|c|c|c|c|}
\hline$\left(\mathrm{g} / \mathrm{m}^{2}\right)$ & $\mathbf{O}_{3}$ & $\mathrm{NO}_{2}$ & $\mathrm{SO}_{2}$ & CO \\
\hline WESROC & 7.9 & 2.2 & 0.43 & 1.9 \\
\hline Beijing, China & 0.8 & 0.4 & 0.3 & - \\
\hline Brooklyn, NY & 0.41 & 0.34 & 0.18 & 0.08 \\
\hline
\end{tabular}

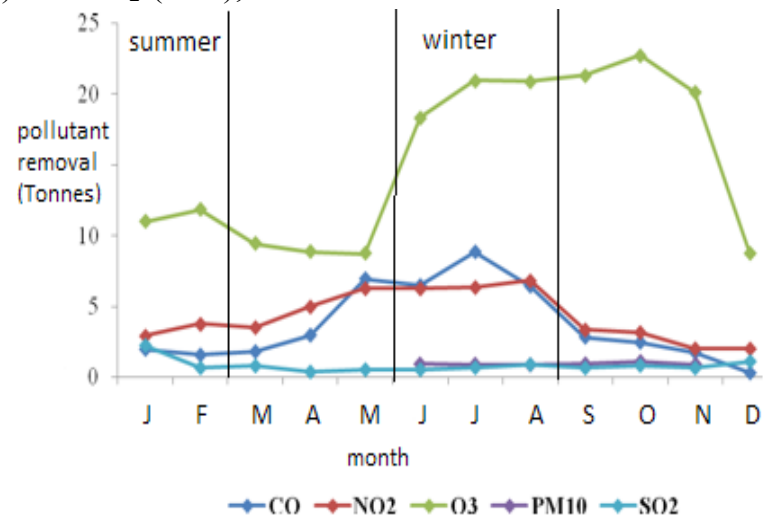

Figure 4. Monthly variation in pollutant removal by vegetation on public land in WESROC. 


\subsection{BVOC Emissions}

Vegetation on public land in WESROC emitted an annual total of 119 tonnes of BVOC, the majority of which was isoprene (81\%). Emissions from trees (104 tonnes) averaged $20.0 \mathrm{~g} \mathrm{BVOC} / \mathrm{m}^{2}$ canopy cover $/ \mathrm{yr}$ while shrub emissions (15 tonnes) averaged $5.6 \mathrm{~g} \mathrm{BVOC} / \mathrm{m}^{2}$ canopy cover $/ \mathrm{yr}$. Emissions of BVOCs were highest in March (24 tonnes) and lowest in July ( 3 tonnes) with variation closely following average monthly temperatures. Monthly and diurnal variation in BVOC emissions can generally be attributed to variations in light intensity and leaf temperature (Guenther 1997). UFORE uses genus-specific emission factors based on taxonomic methodology. Several researchers have used the taxonomic methodology for assigning emission rates where no species measurements are available. The basic principle is that within broad qualitative ranges, taxonomic relationships between plant species at the lowest possible level (genus, then family) can be used to allocate measured emission rates to other species within that level (Benjamin et al. 1996). Analysis revealed Eucalyptus had highest overall BVOC emission $(82,000 \mathrm{~kg} / \mathrm{yr})$, far higher than emissions of any other genera, while Prunus had the lowest overall emissions $(2 \mathrm{~kg} / \mathrm{yr})$. When standardised to $\mathrm{kg}$ BVOC emitted per kg of leaf biomass Eucalyptus, Casuarina (used to represent Allocasuarina species) and Platanus emitted large amounts of BVOC $(0.20,0.19$ and $0.16 \mathrm{~kg} \mathrm{BVOC} / \mathrm{kg}$ leaf biomass respectively), while Prunus, Rosa, Grevillea, Olea, Cupressus and Jacaranda were all low emitters (0.01 kg BVOC/kg leaf biomass).

\subsection{Carbon Storage and Sequestration}

A total of $960( \pm 160)$ tonnes of carbon were sequestered annually by trees located on public land in WESROC. Net annual sequestration (taking into account tree condition) was $810( \pm 140)$ tonnes, or 0.3 $( \pm 0.06)$ tonnes/ha. The net annual sequestration is less than the total carbon sequestration due to the poor condition of vegetation in remnant native vegetation bushland ('poor' or 'dying' condition). For some species a negative sequestration rate was determined as $100 \%$ of the individuals sampled were in a 'dying' condition, hence tree decay and re-release of stored carbon is greater than the amount sequestered annually. Potential release of carbon due to tree death was taken into account using annual mortality rates derived from a previous study. All dead trees on vacant/ transportation land use and 50\% in parks land use were assumed to decompose over a period of 20 years. For all other land uses it was assumed that a dead tree is removed within 1 year of tree death. Total carbon storage was $35,640( \pm 8,280)$ tonnes, with an average of $15( \pm 4)$ tonnes of carbon stored per hectare of land. Carbon storage on a per tree basis was highest in Eucalyptus gomphocephala (2,160 kg carbon/tree) and Ficus rubiginosa (1,920 kg carbon/tree) while Acacia cyclops and Ceanothus verrucosus had the lowest $(7 \mathrm{~kg} / \mathrm{tree})$. The large mature size of both $E$ gomphocephala and $F$ rubiginosa result in a larger amount of carbon stored as biomass. Species with high annual net carbon sequestration included $F$ rubiginosa (33.0 kg carbon/tree/yr) and E leucoxylon (23.0 kg carbon/tree/yr).

\section{SUMMARY AND CONCLUSIONS}

An overall summary analysis of the UFORE model outcomes on the urban vegetation-atmosphere interaction functions in WESROC are; those species best at pollution removal are generally those possessing needle-like leaves, including species such as the Norfolk Island Pine (Araucaria heterophylla) and Allocasuarina fraseriana (Sheoak). Species with this leaf-form are more effective at capturing pollutants (particularly particulate pollutants) than broad-leaved species due to the greater leaf area and higher turbulent flow around the leaf increasing the rate of impaction (Beckett, Freer-Smith \& Taylor 2000). Leaf Area Index (LAI) can indicate which species have the most amount of leaf surface area per ground area, to identify those species which have the potential to improve pollutant deposition. In the species lists complied there were a limited number of low BVOC emitting species (Grevillea sp., Jacaranda mimosifolia) with many of the native vegetation being high BVOC emitters (Allocasuarina, Eucalyptus Melaleuca). Carbon sequestration (per tree) was highest in Norfolk Island Pine (Araucaria heterophylla), Callistemon viminalis, and Lophostemon confertus. Species that maximise one function may not be effective in another. For example several Eucalyptus species have high carbon sequestration rates, but overall Eucalyptus is a high BVOC emitter. There are also several species that maximise more than one function including Araucaria hetrophylla (high LAI, high annual carbon sequestration) and Jacaranda mimosifolia (high annual carbon sequestration, low BVOC emissions). Therefore in planning, final species selection will vary on the specific vegetation function that is of priority; maximising pollutant removal or carbon sequestration, or minimising BVOC emissions.

In conclusion UFORE presents a relatively straightforward method of estimating multiple urban vegetation functions. The study has provided insight into the local atmospheric impact of the current species composition on public land in WESROC. It also identifies those species that are most effective at improving local air quality. A lack of relevant native vegetation data in Australian environments diminishes the effectiveness of UFORE estimates. Through consultation with the USFS the applicability of UFORE in this environment can be improved to enable more widespread use, and incorporation of vegetation into air quality management plans and policy. There are many complex processes involved in both the removal of pollutants 
from the local atmosphere and the emission of BVOCs that are currently unknown. For the WA environment there are physiological differences in vegetation to those of the region for which the UFORE was developed. With limited data available, the nearest similar surrogates had to be used. Also the effect of resource limitations on the local plant growth is also unknown. Further it is difficult to accurately model the dispersion of pollutants at different regional and local small scales. Hence these results provide a first approximation of the influence vegetation has on a local urban atmosphere in WA. A significant contribution to the knowledge of vegetation-atmosphere interactions in a unique Australian environment, including how native vegetation can be incorporated into the model when there is limited physiological research available. The outcomes enable further modelling to increase understanding and quantify the role of urban vegetation in Australia on atmospheric quality and the types of vegetation that will maximise atmospheric benefits.

\section{ACKNOWLEDGMENTS}

To the Western Suburbs Regional Organisation of Councils (WESROC). Thanks to all the field assistants, Al Zelaya (Davey Tree Expert Company) for technical help with the UFORE model, the USFS, R. Hoehn and Dr D. Nowak for data processing. The National Climate Centre, P. Rye, A. Grieco and C. Chambers (DEC, Air Quality Management Branch, WA) and N. Middleton (UWA) for supplying data.

\section{REFERENCES}

Australian Bureau of Statistics, (2009), Commonwealth of Australia. Available from: http://www.abs.gov.au.

Beckett, K.P., Freer-Smith, P. \& Taylor, G. (2000), 'Particulate pollution capture by urban trees: effect of species and windspeed', Global Change Biology, 6, 8, pp. 995-1003.

Benjamin, M.T. \& Winer, A.M (1998). 'Estimating the ozone-forming potential of urban trees and shrubs', Atmospheric Environment, 32, 1, pp. 53-68.

Boentje, J.P. \& Blinnikov, M.S. (2007). 'Post-Soviet forest fragmentation and loss in the Green Belt around Moscow, Russia (1991-2001): a remote sensing perspective', Landscape and Urban Planning, 82, pp. $208-221$

Bokwa, A. (2008). 'Environmental Impacts of Long-Term Air Pollution Changes in Krakow, Poland', Polish Journal of Environmental Studies, 17, 5, pp. 673-686.

Department of Environment and Conservation (2007), 2006 Western Australia Air Monitoring Report, DEC, Perth.

Department of Environmental Protection (2000). Perth Air Quality Management Plan: State of Knowledge, Perth.

Environmental Protection Authority (2007). State of the Environment Report Western Australia, 2007, EPA, Perth.

Fenger, J. (1999), 'Urban air quality', Atmospheric Environment, 33, pp. 4877-4900.

Guenther, A., Hewitt, C.N., Erickson, D., Fall, R., Geron, C. et al. (1995) 'A global model of natural volatile organic compound emissions', Journal of Geophysical Research-Atmospheres, 100, D5, pp. 8873-8892.

Guenther, A. (1997). 'Seasonal and Spatial Variations in Natural Volatile Organic Compound Emissions', Ecology Appications., 7, 1, pp. 34-45.

Kreyling, W.G., Tuch, T., Peters, A., Pitz, M., Heinrich, J., Stolzel, M., Cyrys, J., Heyder, J. \& Wichmann, H.E. (2003). 'Diverging long-term trends in ambient particle mass and number concentrations associated with emission changes caused by the German unification', Atmospheric Environment, 37, pp. 3841-3848.

Myers, N., Mittermeier, R.A., Mittermeier, G.G., da Fonseca G.A.B. \& Kent, J. (2000). 'Biodiversity hotspots for conservation priorities', Nature, vol. 403, no. 6772, p. 853.

National Climate Centre (2008). Commonwealth of Australia, available from http://www.bom.gov.au/climate/

Niemelä, J. (1999). 'Ecology and urban planning', Biodiversity and Conservation, vol. 8, no. 1, p. 119.

Nowak, D.J. (1996). 'Estimating leaf area and leaf biomass of open-grown deciduous urban trees', Forest Science, vol. 42 , no. 4 , pp. 504-507.

Nowak, D.J. \& Crane, D.E. (2000) 'The Urban Forest Effects (UFORE) Model: quantifying urban forest structure and functions', in Integrated tools for natural resources inventories in the 21st century: proc. IUFRO conference, eds Hansen \& Burk, U.S. Department of Agriculture, Forest Service, St. Paul, MN, pp. 714-720.

Nowak, D.J., Crane, D.E., Stevens, J.C. \& Ibarra, M. (2002). Brooklyn's Urban Forest, USDA Forest Service, Pennsylvania, Environmental Pollution, 116, 3, pp. 381-389.

Nowak, D.J., Crane D.E. \& Stevens, J.C. (2006). 'Air pollution removal by urban trees and shrubs in the United States', Urban Forestry \& Urban Greening, 4, pp. 115-123.

Nowak, D.J., Hoehn, R.E., Crane, D.E., Stevens J.C. \& Walton, J.T. (2007). Assessing Urban Forest Effects and Values, San Francisco's Urban Forest, USDA Forest Service.

Nowak, D.J., Crane, D.E., Stevens, J.C., Hoehn, R.E., Walton J.T. \& Bond, J. (2008). 'A Ground-Based Method of Assessing Urban Forest Structure and Ecosystem Services', Arboriculture \& Urban Forestry, 34, pp. 347-358.

Nowak, D.J., McHale, P.J., Ibarra, M., Crane, D.E., Stevens, J.C. \& Luley, C. (1998). 'Modelling the Effects of Urban Vegetation on Air Pollution', International Meeting on Air Pollution Modelling and its Application XII.

WESROC (2002). The Western Suburbs Greening Plan, Prepared by Ecoscape.

White, R.R. (1994). in Urban Environmental Management: Environmental Change and Urban Design, Wiley, NY.

Yang, J., McBride, J., Zhou, J. \& Sun, Z. (2005). 'The urban forest in Beijing and its role in air pollution reduction', Urban Forestry \& Urban Greening, 3, 2, p. 65.

Yimin, M. \& Lyons, T. (2003). 'Recirculation of coastal urban air pollution under a synoptic scale thermal trough in Perth, Western Australia', Atmospheric Environment, 37, pp. 443-454 